\title{
Rifampicin-induced urticaria in leprosy
}

\author{
VINOD K SHARMA, INDERJEET KAUR, \\ MANEESHA VATVE, BHUSHAN KUMAR \\ Department of Dermatology, Venereology \& Leprology, Postgradu- \\ ate Institute of Medical Education and Research, Chandigarh- \\ 160012, India
}

\section{Accepted for publication}

A 28-year-old housewife from Uttar Pradesh, India had suffered from lepromatous leprosy with necrotic erythema nodosum leprosum (ENL) for the last 2 years. Her bacteriological and morphological indices were $4+$ and $1 \%$, respectively and a skin biopsy confirmed the diagnosis of lepromatous leprosy with ENL. Her renal, hepatic and haematologic parameters were within normal limits except for haemoglobin of $8 \mathrm{~g} \%$. She was started on WHO-MBR (rifampicin, dapsone and clofazimine) and prednisolone $40 \mathrm{mg}$ daily. Within half an hour of the first loading dose the patient developed severe itching over the trunk and extremities followed by urticaria. There was no rhinorrhoea, fever, bronchospasm or hypotension. Urticaria subsided within 4-6h after administration of an antihistaminic and there was no recurrence of symptom during daily intake of dapsone and clofazimine. Urticaria recurred within $30 \mathrm{~min}$ of the $2 \mathrm{nd}$ and $3 \mathrm{rd}$ loading doses and increased in severity. Urticaria did not recur when rifampicin was omitted from the 4th loading dose onwards. Patient was treated with oflaxacin $400 \mathrm{mg}$ daily for 8 weeks and continued on dapsone and clofazimine. There was no recurrence of urticaria during 2 years follow up.

An open patch test and prick test with rifampicin dissolved in acetone was negative but administration of $300 \mathrm{mg}$ rifampicin under observation lead to the development of itching and urticaria within $30 \mathrm{~min}$.

\section{Discussion}

Side-effects of rifampicin are well documented and occur more frequently with intermittent administration especially flu syndrome, shock, shortness of breath, haemolytic anemia and renal failure. ${ }^{1-3}$ Daily and intermittent administration also gives rise to cutaneous and gastrointestinal syndrome, hepatitis and purpura. ${ }^{4}$ Cutaneous syndrome includes itching and flushing of face and it may be associated with rash. Patients may develop hypersensitivity syndrome, Steven's Johnson Syndrome, pemphigus, porphyria cutanea tarda and acneform eruption. Rarely it can induce neutropenia, agranulocytosis; thrombocytopenia, eosinophilia, 
psychosis, osteomalacia and adrenal crisis. ${ }^{3,5}$ Recently one patient with impaired blood clotting associated with fever, chills and hypotension has been described with intermittent rifampicin therapy. ${ }^{6}$ There are isolated reports of urticaria and anaphylaxis due to rifampicin in the literature. ${ }^{7,8}$ Type I hypersensitivity especially anaphylaxis is rare with rifampicin therapy and accounted for only 6 out of 30,000 possible allergic reactions to rifampicin. It is more common with intermittent therapy and associated HIV infection. ${ }^{9}$ In a recent study of adverse effects of WHO multidrug therapy for leprosy, hypotension was recorded in 3 and urticaria in 6 cases in a study of 20,667 patients in Sao Paulo, Brazil. ${ }^{10}$ It was, however, not clear whether all these were attributable to rifampicin. We have observed only one patient with Type I hypersensitivity after treatment of more than 2500 patients with WHO-MDT over the last 14 years. Cases of shortness of breath described in literature probably are not Type I hypersensitivity as the majority of them occur in association with flu syndrome and may not be associated with wheezing. We believe that this is the first case report of rifampicin-induced urticaria from India. It is possible our patient could have developed more serious symptoms like anaphylaxis but for concurrent administration of $30-40 \mathrm{mg}$ prednisolone throughout the course of illness because of necrotic erythema nodosum leprosum. Prednisolone may have also interfered with results of prick test, provocation was however, positive with rifampicin. The aim of present communication is to re-emphasize to all the clinicans and paramedical workers in remote areas to watch out for rare occurrence of rifampicin-induced urticaria and anaphylaxis.

\section{References}

${ }^{1}$ Poole G, Stradling P, Worlledge S. Potentially serious side effects of high dose high dose twice weekly rifampicin. Brit. Med. J. 1971; 3: 343-347.

2 Aquinas SM, Allan WGL, Horsfall Pal, Jenkins PK, Hung-Yan W, Girgling D, Tall R, Fox W. Adverse reactions to daily and intermittent regimes for pulmonary tuberculosis in Hong Kong. Brit. Med. J. 1972; 1: 765-771.

3 Dhar S, Kaur I, Sharma VK, Kumar B. Flu syndrome due to rifampicin: experience of 4 cases. Int. J. Lepr. 1995; 63: $92-94$.

4 Jopling WH. Reference to side-effects of antileprosy drugs in common use. Lepr. Rev. 1985; 56: 61-70.

5 Vijaykumaran P, Manimozhi N, Jesudasan K, Arunthathi S, Jacob M, Samuel P. Leucocytopenia and rifampicin and ofloxacin therapy in leprosy. Lepr. Rev. 1997; 68: 10-15.

6 Sule RR. An unusual reaction to rifampicin once monthly dose. Lepr. Rev. 1996; 67: 227-228.

7 Harland RW, Lindblom SS. Anaphylaxis from rifampicin. Am. J. Med. 1992; 92: 581-582.

${ }^{8}$ Nessi R, Domenichini E, Fowst G. "Allergic" reactions to rifampicin treatment: a review of published cases. Scand. J. Respir. Dis. 1973; 84 (suppl): 15-19.

9 Wurtz RR, Abrams D, Becker S, Jacobson MA, Mass M, Marks SM. Anaphylactoid drug reaction to ciprofloxacin and rifampicin in HIV infected patients. Lancet 1989; 1: 955-956.

10 Brasil MTLRF, Opromolla DVA, Marzilak MLC, Nogueira W. Result of surveillance system of adverse effects in leprosy's WHO/MDT. Int. J. Lepr. 1996; 64: 97-104. 